\title{
Personality identity in the terms of virtualization of being
}

\author{
Zinaida Ryabikina ${ }^{1,{ }^{*}}$ and Ekaterina Bogomolova ${ }^{1}$ and Lyudmila Ozhigova ${ }^{1}$ \\ ${ }^{1}$ Kuban State University, 149 Stavropol'skaia St., Krasnodar, 350040, Russia
}

\begin{abstract}
The Internet users have been studied in the terms of a positive or negative impact on personality existence and co-existence in the context of virtual reality. Personality activity focus on backing up their own identity during the interaction with the Other in the virtual co-existence space. The web content mining of opinions expressed by social networks on thematic forums shows that major activity drivers in the virtual space of social networks are communicative, affiliative and self-assertive drivers. This is due to a personality's aim at backing up their identity in co-existence with the Other. The FIRO-B questionnaire has revealed relevant dominance of virtual communication participants' own activity over activity expected from their communication partner regarding the scales of inclusion and control. The opportunity to be an agent for "both" (themselves and their virtual communication partner) in the fields of inclusion and control makes it easier to gain a personality's required confirmation of their identity in relationship with the Other as well as get reassured that their being has been successfully extended into the Other's agent world (to personalize). Virtualization of a personality's relationship carries risks for identity being simulated due to non-availability of a true dialogue with the Other.
\end{abstract}

\section{Introduction}

\subsection{Virtual reality is a new existence reality of a present-day person}

Please note that the first paragraph of a section or subsection is not indented. The first paragraphs that follows a table, figure, equation etc. does not have an indent, either.

Every culture is characterized by technologically new means of being-in-the-world. Today we are considering a new reality where a present-day person forms up their being. That entails hyper reality [1], cyberspace [2], space of simulacrum [3], virtualization of society etc. [4].

The widely-known Independence Declaration of Cyberspace by John Perry Barlow announced the dawn of a new era for humans - the up rise of the virtual social reality [5].

The new virtual world is promising and brings out great opportunities for cooperative unity and uniqueness all in one [6].

\footnotetext{
* Corresponding author: z.ryabikina@yandex.ru
} 
Through the virtual reality technology a person is enabled to experience their existence in a new way. Virtual space has an impact on transformation of a person's impression and perception, on awareness of the self being in the world [7;8].

Network users describe their trials as a sort of enlarging their mind and character, as broadening the inward man. The Internet has power to make a person stronger by way of extending opportunity to form up communities, start up cooperative venues and actions [9; $10]$.

On the other hand, continual being on-line can flood consciousness with overflows of unnecessary information [11]. This sets up a claim for the ability to build up a filter which would pass or halt anything into a person's consciousness [12].

How are expressions of a person's activity being on-line and off-line interconnected? Are there any reasons to anticipate that a person's on-line activity causes dropping of their offline activity? From this perspective the issue appears ambivalent. In the discussions on the subject challenges and opportunities can be presented as a vision of the future.

\subsection{Growth of a personality's agency-active in the context of virtual existence reality}

On the one hand, the statement of a person's agency growth sounds valid. It is proved by the following: a person's involvement in the digital reality as a vigorous actor (agent), possibility to adjust the technology of interactive digital networks to their own needs and their set of personal values. A particular person who has mastered the necessary knowledge and skills creates their own virtual reality, their own world where their inward life takes shapes to the fullest extent.

Thanks to the virtual reality technology mental structure of a certain person becomes potentially more agency-active and this person becomes a potentially more dynamic agent who affects sequencing events.

\subsection{Deprivation of a personality's agency-active in the context of virtual existence reality}

On the other hand, obscure scenes of anomie due to the deprivation of a person's agency are overwhelming in future forecasts, in art representations of the future. Such feature pictures as The Terminator, Matrix, Neuromancer thrill spectators' and readers' minds with their apocalection. Fear of losing the ability to be an agent (an actor) of one's being is depressing [13].

Virtual reality appears to be a simulacrum space, i.e. the very same fictional reality that can be so attractive that the true world with its difficulties and contradictions gives way to simulation. Herewith, action determinacy becomes distorted, a person's responsibility for the latter fades away. In the virtual space a person arranges relationship with the world in a manner that they feel easily and comfortable. However, this sweet triumph is only a phantom just as the virtual reality itself, unless the achievements gained on-line expand a person's offline being opportunities.

\subsection{Focus of a personality's agency-active on backing up their identity in co- existence with the Other}

What makes a person be highly interested in communication in the virtual space of being? The personality's agency-active determined by their need for backing up their identity in coexistence with the Other. The Other is always a necessary actor for a person, the one who can 
confirm their identity and thus prolong their being in the way the person views themselves (self-image), or it can "break" their being in that particular image [14].

It can be assumed that the opportunity to gain a person's demandable confirmation of their identity via relationship with the Other is more successfully realized in the virtual communication. A person's desirable extent of their being into the Other's subjective world, or personalization, proves to be easier achievable in virtual co-existence within the Internet communication.

Possibility to create the wished-for impression about themselves, apportioned selfunfolding and a voluntarily forming up their image, ability to manipulate the identity being formed up is still one of the most catching aspects of a person's virtual being $[15 ; 16]$.

In the Internet, people shape a sort of virtual personalities due to which the question that has to be answered is how the real Self corresponds to the virtual models and where the borderline between self-introduction, simulation, self-actualization in these games and the real identity is.

This virtual life makes a person either anonymous or, by contrast, "crystal clear". The research based on volunteers' Face book profiles proves that it is easy to foretell users' ethnic origin, religious affiliation, sexual identity and their personal attributes following on from the data specified in them [17]

Development of virtual space functionality is due to meeting users' demand. John Barlow remarks that first of all these interests are aimed at making virtual communication as much as possible alike the natural one (as in a person's real existence): seeing interlocutor's face, 3 -dimensional picture and so on [18].

However, it is only an external (technical) aspect of the development. It intensifies illusion of faithfulness of a virtual communication partner's view in the reality, though it does not ensure that faithfulness. A person's fictitious self-identification can be backed up in the virtual communication insofar as the person directs their contacts, decreases potential attacks from a partner using available means, avoids the chance of being understood by their partner. The possibility to make manipulations in the terms of self-identification through various strategies and tactics of self-presentation is reserved. Users of virtual social networks experience new aspects with regards to correspondence between their own agent's (actor's) behavior and that expected from the partner.

This essay provides the research results aimed at studying special aspects of social networks users' interpersonal behavior and the nature of interpersonal positioning.

\section{Methods}

On-line world has become a complicated social reality being built up according to its own laws which are sometimes difficult to study by means of traditional quantitative models and require qualitative research methodology to be use. Web content mining of opinions expressed by users of several social networks and thematic forums has been performed in this research. Thus, inducements have been uncovered that impel a person to get involved in a communication of the kind. 416 replies (among 176 men, 208 women, 32 without gender specified) were analyzed.

There is a major methodology concern related to selection and usage of psychological means in cyber psychology for studying users' personal attributes and their inducements. Big Five Personality Model is the most frequently used and suitable for this goal. More and more researchers find corresponding personal traits to their behavior in social networks to be a resource $[19 ; 20]$.

Nevertheless, the approach does not enable to bring to light that driving, active (agent's) component of a person's behavior in the Internet communication.

This research is based on using FIRO-B methodology developed by W. Schutz. 
The above mentioned questionnaire is designed to evaluate a person's behavior in the field of the three major interpersonal needs:

inclusion (I) - need for formation and support of relationship with other people;

control (C) - demand for controlling the nature and special aspects of relationship with others;

affect (A) - need for formation and support of relationship based on love and intimate affective communication.

The two interpersonal behavior trends taken into consideration within each field are: $a$ person's behavior patterns (ethics) (e) - the person's view of intensity of their behavior in the field under consideration; behavior desirable and wanted by the person from public (w) of the intensity being preferable for the person.

Thus, the replies are estimated according to the following scales:

Ie - a person's behavior in the field of inclusion;

$\mathrm{Iw}$ - behavior required from a partner in the field of inclusion;

$\mathrm{Ce}-\mathrm{a}$ person's behavior in the field of control;

$\mathrm{Cw}$ - behavior wanted from others in the field of control;

$\mathrm{Ae}-\mathrm{a}$ person's behavior in the field of affect;

Aw - behavior waited from others in the field of affect.

Following on from the scales peculiar aspects of interpersonal actions of those surveyed and the behavior they prefer to see from their communication partners have been described. 70 persons aged between 19 and 25 ( 25 boys, 45 girls) took part in the research. All the responders labeled themselves being active Internet communication users.

\section{Results}

The arrangement of the replies by users of several social networks (frequency of demonstration of users' inducements being indicated) results in as below:

Communicative inducement $-90.6 \%$;

Affiliative need driver $-46 \%$;

Self-assertive ambition (all too often in a negative context) $-41.5 \%$;

Cognitive driver $-39.5 \%$;

Self-actualization and personality advancement driver $-27.6 \%$;

Corporate inducement $-15 \%$;

Recreational or play driver $-4 \%$;

Business inducement- $0.3 \%$.

The first three lines of the list above (and so considered to be major person's activity inducements in the virtual social networks) are communicative, affiliative and self-assertive drivers. It all goes to show that communication within social networks provides a person with an opportunity to settle their current communicative issues as well as experience participation in relevant groups.

Responders showed higher indices of intensity of their behavior in the field of inclusion (Ie) and low ones on the scale of behavior wanted from their partners in the field of involvement ( $\mathrm{Iw}$ ): boys $-\mathrm{Ie}-\mathrm{m}=5.16$, $\mathrm{Iw}-\mathrm{m}=4.16$; girls $-\mathrm{Ie}-\mathrm{m}=5.13, \mathrm{Iw}-\mathrm{m}=4.13$. The difference between the figures is essential (Student's t-test being used) whether boys' $(\mathrm{p}<0.005)$ or girls' $(\mathrm{p}<0.001)$.

The findings prove that those surveyed endeavor to get inclusion in interpersonal relations, long for engagement. They consider themselves more active at that and low down the activity coming from their communication partners. So, they expect a less relation inclusion activity from public, but prefer to choose (by their own) partners to form and back up mentally comfortable communications as well as to have a chance to stop these relations if necessary. 
According to the scale of intensity of the person's own behavior in the field of control (Ce) and behavior wanted from a partner in the field of control $(\mathrm{Cw})$ the group of boys showed lower figures than those of the girls group: boys $(\mathrm{Ce})-\mathrm{m}=5.12$, girls $(\mathrm{Ce})-\mathrm{m}=5.73$. This can be explained as a more intense desire for control over relations in the virtual space on the part of the girts.

Correlation of indices on the control scale with what an agent (actor) is aimed at (Ce) and what they want from their virtual partner $(\mathrm{Cw})$ lies upon the following average figures: boys $-(\mathrm{Ce})-\mathrm{m}=5.12,(\mathrm{Cw})-\mathrm{m}=3.32$; girls $(\mathrm{Ce})-\mathrm{m}=5.73,(\mathrm{Cw})-\mathrm{m}=3.53$. The diversity on the scale $\mathrm{Ce}-\mathrm{Cw}$ in the group of boys $(\mathrm{p}<0.01)$ is greater than that of the group of girls $(p<0.0005)$. The findings point to the fact that both boys and girls strive to control their relations in communication. They consider themselves in this manifestation to be more active than they expect their partners to be.

With regard to a person's own intense behavior (Ae) and that wanted from a partner (Aw) in the field of affect, those surveyed showed the following data: boys (Ae) $-\mathrm{m}=2.96$, (Aw) $-\mathrm{m}=4.48$; girls $(\mathrm{Ae})-\mathrm{m}=3.75$, (Aw) $-\mathrm{m}=4.53$.

With that said, both boys and girls demonstrate statistically significant diversity on the two scales studied $(\mathrm{p}<0.05)$. What tells the results on the affect scale from the results on the two previous scales (inclusion and control) is willingness to depute bigger activity to their communication partner and their own reduced activity in the field (Ae).

Thus and so, either girls or boys seriously trend to show activity in the fields of inclusion and control in the virtual communication and demonstrate a more passive position in the field of affect, expressing love, fellow-feeling and expect their partners to be more energetic in this field.

That is the possibility to be an agent (actor) for both (themselves and their virtual communication partner) in the terms of inclusion and control that makes it easier to gain the person's necessary confirmation of their identity through relations with the Other, as well as to get assured that the person did manage to extend their being into the Other's subjective world (to personalize).

The Internet is an arrangement that is fraught with a dangerous possibility of replacement the real communication and dialogically structured society with a society where that structure is unnecessary and can be avoided. In virtual social networks relations give growth to wouldbe cultural communication where a conversation is performed according to concurrent or almost concurrent semantic structures with "the Other like Self". This eliminates contradictions that are natural in real communication with others and which, being settled through a dialogue with the Other, ensure development of a person's semantic field and personal advancement. Therefore, virtualization of a person's relationship is perilous for a person as it can simulate their agency-activity or distort their agency focus due to the lack of the true conversation with the Other.

\section{Discussion and Conclusions}

There and then, the research shows that major personality's agency-active inducements in the virtual space of social networks are communicative, affiliative and self-assertive drivers. In particular, this is due to the fact that a person's agency-activity is determined by its focus on backing up their identity in co-existence with the Other. An opportunity to act as an agent for both (themselves and their virtual communication partner) in the field of inclusion and control makes it easier to gain the person's wanted confirmation of their identity through relation with a virtual communication partner, as well as to get assured that they managed to expand their being into the Other's subjective world (to personalize). With that, virtualization of a personality's relationship can be dangerous as a simulation of a person's agency or distortion of their agency focus because of lack of the real dialogue with the Other. 
To conclude, the undertaken research as well as the analysis of other works prove that the Internet communication or a personality's "life" in the virtual space can be smoothly combined with the off-line life providing that it becomes an extra resource; gives information, means and methods; improves person's being; increases chances for their self-realization and achieving authenticity. Though there are risks of being deadlocked in the virtual space, of segregation of a particular existence aspect (virtual existence), when communication in the virtual environment stops being a tool, a means of enlarging a person's real-life potential but turns into extensial all-sufficient demand that conquers a person, makes them dependent on and addicted to new gadgets, computer programs, fictitious self-identities that are backed up by their virtual communication partners. So, in the first case as an agent and in the second case as a false-agent person's position in the virtual space of being determines the person's real being, a full value of the latter or a zero value (replication if compared to on-line being).

\section{References}

1. G. Deleuze, Cl. Parnet, Dialogues II (Columbia University Press, New York, 2007)

2. W. Gibson, Neuromancer (Orion Publishing Group, 2016)

3. D. Keller, J. Baudrillard, From Marxism to Postmodernism and Beyond (Polity Press and Stanford University Press, Cambridge and Palo Alto, 1989)

4. Y.P. Zinchenko, G.Y. Menshikova, Y.M. Bayakovsky, A.M. Chernorizov, A.E. Voiskounsky, Psychology in Russia: State of the Art 3,12-45 (2010) https://doi.org/10.11621/pir.2010.0001

5. J.P. Barlow, A Declaration of the Independence of Cyberspace, https://www.eff.org/cyberspace-independence

6. K. Kelly, The New Socialism: Global Collectivist Society Is Coming Online https://www.wired.com/2009/05/nep-newsocialism/

7. L. Shaigerova, R. Shilko, O. Vakhantseva, Y. Zinchenko, National Psychological Journal 12(3), 4-16 (2019) https://doi.org/ 10.11621/npj.2019.0302

8. A. Voiskounsky, M. Kutuzova, E. Sveshnikova, Journal of Behavioral Addictions 6(1), 58 (2017)

9. B. Hood, I Can Make A Difference Because of The Internet. Edge, https://www.edge.org/response-detail/10736

10. D. Bell, An Introduction to Cybercultures (London, 2001)

11. E.V. Patrakov, Sibirskiy Psikhologicheskiy Zhurnal - Siberian journal of psychology 72 , 129-144 (2019) https://doi.org/10.17223/17267080/72/7

12. H. Rheingold, Attention Is The Fundamental Literacy. Edge, https://www.edge.org/response-detail/11370

13. S.Y. Guo, Psychology in the Schools 53(4), 432-453 (2016) https://doi.org/10.1002/pits.21914

14. J. McLeod, Qualitative Research in Counselling and Psychotherapy (SAGE, Lnd, 2011)

15. A.G. Asmolov, G.A. Asmolov, Psychology in Russia: State of the Art 2, 101-123 (2013) https://cyberleninka.ru/article/n/from-we-media-to-i-media-identity-transformations-inthe-virtual-world

16. D. Foster, Can We Have Communities in (Cyber) Space? Carleton University Working Papers in Communication Technology and Culture (1995) 
17. M. Kosinski, D. Stillwell, T. Graepel, Proceedings of the National Academy of Sciences of the United States of America 110(15), 5802-5805 (2013) https://www.pnas.org/content/110/15/5802

18. J.P. Barlow, Is there a there in cyberspase? https://www.utne.com/community/isthereathereincyberspace

19. D. Azucar, D. Marengo, M. Settanni, Personality and Individual Differences 124, 150159 (2018) https://doi.org/10.1016/j.paid.2017.12.018

20. R. Gao, B. Hao, S. Bai, L. Li, A. Li, T. Zhu, RecSys '13: Proceedings of the 7th ACM conference on Recommender systems (2013) https://doi.org/10.1145/2507157.2507219

21. L. Li, A. Li, B. Hao, Z. Guan, T. Zhu, PLOS ONE 9(1), e84997 (2014) https://doi.org/10.1371/journal.pone.0084997 